\title{
Self-Injury in Japanese Manga: A Content Analysis
}

\author{
Yukari Seko $^{1} \cdot$ Minako Kikuchi $^{2}$ \\ Published online: 10 January 2020 \\ (C) Springer Science+Business Media, LLC, part of Springer Nature 2020
}

\begin{abstract}
This study explored representations of self-injury in Japanese manga (graphic novels). A content analysis of fifteen slice-of-life manga published between 2000-2017 was conducted, focusing on forty scenes that depict eighteen characters engaging in self-injury. Most depictions of self-injury reflect a stereotypical perception of "self-injurer," a young girl cutting herself to cope with negative emotion. Characters receive informal support from friends and partners, while parents are portrayed as unsupportive and even triggering. An emergent trend was observed among manga targeting male readers to label selfinjuring women as "menhera" - mentally vulnerable damsels in distress - inviting a fetishistic gaze on the self-injuring female bodies.
\end{abstract}

Keywords Manga $\cdot$ Self-injury $\cdot$ Content analysis $\cdot$ Japanese popular culture

\section{Introduction}

As I watched the blood drip... And drip... It was like all the mixed-up thoughts in my head... were flowing out of me.

The only thing that makes me feel better... is pain. If I want to know what it's like to get hurt... I have to experience it firsthand.

- LIFE (Suenobu 2002, 85, 97)

After slicing her arm with a box cutter, Ayumu, a fifteen-year-old high school girl crouches on the floor, leaning against the bed. As the pent-up emotion that occupied her a moment ago

Yukari Seko

yseko@ryerson.ca

Minako Kikuchi

mkikuchi@ncnp.go.jp

1 School of Professional Communication, Ryerson University, 350 Victoria St, Toronto, ON M5B 2K3, Canada

2 Department of Drug Dependence Research, National Institute of Mental Health, National Center of Neurology and Psychiatry, Tokyo, Japan 
dissolves with the blood flowing out, so does the imagined face of her former best friend staring at her with hatred. As tears flow from her eyes, Ayumu starts sobbing, 'I'm sorry... I'm sorry..." over and over again (Suenobu 2002, 87).

Ayumu's self-cutting, portrayed in a Japanese manga (graphic novel), LIFE (Suenobu 2002-2009; 20 volumes), vividly represents increased public attention toward this new "epidemic" among adolescents and young adults (Brumberg 2006). Since the early 1990s, medical and public health communities across the world have reported the growth of selfinjury, the deliberate hurting of one's body by cutting, burning, self-bruising or other methods. While self-injury affects all age groups, research has consistently shown high prevalence among youth. In a systematic review of one hundred nineteen epidemiological studies across eighteen countries, the mean lifetime prevalence of self-injury (i.e., reporting at least one selfinjuring episode in lifetime) was estimated to be on average $17.2 \%$ among adolescents (ten to seventeen years old) and $13.4 \%$ among young adults (eighteen to twenty-four years old), compared to 5.5\% among adults (twenty-five years or older) (Swannell et al. 2014). Although the definition of self-injury has been the subject of contested debate (Chandler, Myers and Platt 2011), it is now widely accepted that most acts of self-injury represent behavioural problems distinct from suicide attempts (Nock et al. 2006) and are distinguishable from culturally sanctioned self-mutilations such as tattooing or body piercing (International Society for the Study of Self-Injury 2018). ${ }^{1}$

While most existing prevalence studies are done in North America (Swannell et al. 2014; Muehlenkamp et al. 2012), a handful of epidemiological studies have originated in Japan, a country in which mental illness is considered the fifth "priority disease" for national medical service (Ito et al. 2013). Okada et al. (2010) reported a lifetime prevalence rate of $8.2 \%$ from a sample of Japanese junior high school students ( $n=2206$, age range: twelve to fifteen). Similarly, in a study of 1784 junior and senior high school students (mean age: 14.5, age range twelve to seventeen), a lifetime prevalence rate of self-cutting was $9.9 \%$ (Matsumoto et al. 2008), which is slightly higher than the prevalence rate of $6.9 \%$ among 540 college students (Yamaguchi et al. 2004). According to two systematic reviews of prevalence studies across geographical regions (Swannell et al. 2014; Muehlenkamp et al. 2012), these estimates are slightly lower than those reported in North America, Europe, and other East Asian countries. Nonetheless, mounting anecdotal evidence from health professionals and educational specialists suggests that the number of youth engaging in self-injury may have been rapidly increasing in Japan, perhaps outpacing research and clinical efforts (e.g., Ishige 2006; Takahashi and Fujiu 2015; Asano 2015). According to a survey with school counselors at junior high and high school levels, over $98 \%$ of the respondents reported experiences working with students who self-injure (Matsumoto, Imamura, and Katsumata 2009).

Although it is not clear why self-injury has rapidly gained public visibility over a relatively short period of time, it is quite possible that media portrayals, especially visual depictions of people who self-injure, have contributed to this growing public awareness. In their analysis of English movies, TV shows, music, and print news featuring self-injuring characters, Whitlock et al. (2009) identified a clear upward trend in the amount of media content featuring self-injury since 2000. There were twenty movies with explicit references to self-injury in the 2000-2005 period alone, whereas prior to the 1990s only two movies in the sample portrayed self-injury.

A corpus of research indicated that depictions of self-injury in movies and TV shows are often stereotypical and misrepresentative, as the self-injuring characters were predominantly "White female cutters" in their teens or early twenties (Whitlock, Purington, and Gershkovich 2009). This finding was replicated in another content analysis of forty-one English films 
wherein the stereotype of young women cutting themselves to mitigate acute negative emotion was readily prevalent and persistent (Trewavas, Hasking, and McAllister 2010). Feminist scholars have problematized the gendered and racially-skewed representation of the "selfinjurers" in popular media. Brickman (2004) contends that media portrayal of self-injurers as vulnerable young girls perpetuates the "delicate cutter" myth that reproduces a patriarchal assumption of female passivity. Echoing Brickman and other feminist thinkers, Bareiss (2017) also argues that representations of self-injury in popular Hollywood films, though somewhat challenging societal norms, ultimately reinforce normative expectations of young women who self-injure to be docile and submissive.

Compared to the Anglophone mediascape, little is known about how self-injury is represented in Japanese popular culture. Among many visual forms, $m a n g a^{2}$ has become one of the most influential media outlets, due to its large and lucrative market, ${ }^{3}$ entertainment value, affordability, and unique visual language representing internal thoughts and emotions of characters (Cohn 2010). Manga has been instrumental in building a shared cultural space among Japanese readers, covering virtually all topics imaginable, including sports, war, corporate life, child rearing, sex, cooking, usury, and medicine. Beyond entertainment, manga plays a wide array of roles in Japanese society - from a teaching tool, an information source, a behaviour guide, social commentary, an agent of socialization (Ito 2005), to a vehicle for government policy (Matanle, Ishiguro, and McCann 2014).

One notable characteristic of manga is its division of genres by gender and age. Most manga first appear as a series in comic magazines, which are grouped by their gender-based readership, namely, magazines for men (dansei-shi) and for women (josei-shi). Each category is further divided into age-based subgenres including: shōnen manga (boy's comics targeting readers eighteen years old and younger), seinen manga (comics for young males age eighteen to thirty), seijin manga (comics for grownups), shöjo manga (comics for girls eighteen years old and younger), josei manga (comics targeting young female adults age eighteen to thirty), and redicomi ("Lady's Comic" for adult women). Shōnen and shōjo manga targeting young readers generally refrain from explicit nudity, violence and sex, while manga for adult audiences may carry R18 content.

Although Japanese consumers increasingly engage in cross-age, cross-gender readership, the gender-/age-based heterosexual marketing genres still firmly shape the styles and aesthetic of manga. For example, female characters in shojo manga tend to embody societal appearance norms, particularity girlish-cuteness ("kawaii”) culture typified by large staring eyes, frilly dresses, flowers, ribbons and hearts (Kinsella 1995). Traditional gender perceptions manifest more conspicuously in boys' and men's manga, in which female characters use a stereotypical feminine speech style more frequently than has been reported for natural speech (Unser-Schutz 2015). Working women in best-selling men's manga are typically portrayed as either excluded from careers or negatively constructed as being too masculine (Matanle, Ishiguro, and McCann 2014). Stereotypical gendering may also occur on the creator's side, as manga authors are likely to draw for audiences of their own gender. In other words, shōjo manga are generally considered as comics "for girls, by girls," while shōnen manga are comics "for boys, by boys, about boys" (Unser-Schutz 2015), based on a marketing assumption about readers relating to the characters of their own gender.

Like any other form of fictional literature and popular art, manga is deeply immersed in a particular social environment. It constantly reproduces dominant norms, cultural values and beliefs, including socially-embedded heteronormative gender norms and sexism, while offering readers an escape into an imaginative realm to pursue their desires and aspirations beyond 
the limitations set by societal norms. Indeed, what manga offers goes beyond mere escapism; via authentic depiction of a "Japanese way of life" (Ito 2005), it not only confirms social order but also challenges readers to reconsider the taken-for-granted worldviews, social hierarchy and norms. For Masuda (2015), manga's character-based narrative allows readers to "experience different types of the "I" and "relate to the world by simulating the characters' thoughts and relationships" (28) and invites readers to reassess their everyday life and explore alternative ways of being.

Manga serves as a window to Japanese way of life that simultaneously conforms to and challenges societal norms and values, making this cultural artifact particularly optimal for analyzing a topic of interest in situ. While a few previous studies examined iryō-kei manga (medical comics) featuring medical professionals (e.g., doctors, nurses, pharmacists) (Kishi et al. 2011; Matsuoka, Smith, and Uchimura 2011), little has been explored about how manga depicts a public health issue such as self-injury in everyday life context. Literature on the topic of self-injury in manga is virtually nonexistent. We were able to locate one brief report (written in Japanese) by Ishige (2006) that examines self-cutting portrayed in shöjo manga published between 1973-2005, along with folklore and popular songs. Looking at shōjo manga featuring wrist-cutting, Ishige asserts that the meaning ascribed to self-injury has been changing over time from a suicide attempt to a coping strategy. However, although Ishige's study offers a meaningful introduction to this largely under-explored topic, the author does not provide a detailed documentation of the search strategy, analytic method, and the content of manga examined. It remains unknown as to what types of characters were depicted to engage in selfinjury and which set of meanings were associated with the act in each narrative. In addition, there seems to be a significant increase in the volume and variety of manga featuring selfinjury since Ishige's study, especially in genres other than shöjo manga.

The purpose of the present study was thus to examine how self-injury has been represented in Japanese manga since 2000 through a thorough exploration of character demographics, perceived functions of self-injury, and help-seeking behaviours among self-injuring characters within each manga narrative. This study also intended to expand the scope from shojo manga to encompass other types of manga targeting different audiences in terms of gender and age. Given the gendered nature of manga, one can hypothesize that boys' manga and girls' manga may differ in portraying characters who self-injure, as well as meanings ascribed to each act. Exploring the content of manga featuring self-injury thus leads to an important realization about how this mass medium constructs a perceived reality of self-injury, and in so doing, shapes public perceptions of this phenomenon.

\section{Methods}

\section{Data collection}

To date, there is no comprehensive database for Japanese manga. The sources of data for this study were determined through various methods to enhance sampling validity. We first searched three digital databases for manga, the Japan National Diet Library's online catalogue (http://www.ndl.go.jp/), the Japanese Agency for Cultural Affairs' media arts digital archive (https://mediaarts-db.bunka.go.jp), and Kyoto International Manga Museum's Manga Repository (http://mmsearch.kyotomm.jp/index j.html), using the term "jisho" (self-injury). We also consulted with librarians at six Japanese libraries with extensive manga collections. 
Two out of the six libraries, the Osaka Prefectural Library and the Kyoto International Manga Museum, provided us with a comprehensive list of manga that might meet our eligibility criteria below. Additionally, we sought eligible manga by conducting a Google search, visiting online communities where members discuss manga/comics, movies and books featuring selfinjury (e.g. Self-Injury.net), circulating general inquiries among our professional and personal networks, and consulting relevant literature on visual representations of self-injury.

While the narrative review by Ishige (2006) covered shöjo manga published between 1973$2005,75 \%$ of the samples were published prior to 2000. Similar to what Whitlock et al. (2009) reported in their study of English movies featuring self-injury, since 2000 we have noticed a clear upward trend in the amount of manga portraying self-injury. To update and expand Ishige's work, we chose to analyze manga published between 2000 to 2017, and broadened the focus to include other marketing genres than shöjo manga, such as shōnen manga, seinen manga, and Boy's Love, a subgenre of josei manga featuring homoerotic relationships between male characters. As we were most interested in depiction of self-injury in everyday life contexts, we limited our focus onto nichijo-kei ("slice-of-life") genre that features realistic depictions of everyday life, excluding science fiction, fantasy, picaresque romance and other genres that take place in imaginary worlds. Manga featuring overt suicide attempts and culturally sanctioned forms of self-mutilation (e.g. tattooing, body-piercing) were also excluded. As such, our sample did not include a distinct manga genre featuring Yakuza (Japanese mafia) and Yankee (gangster) subculture that frequently portray ritualistic self-injury including yubitsume (a ritual of finger amputation to atone for one's misdeed) or konjo-yaki (a test of courage by burning skin with a cigarette). These self-mutilation rituals serve as staples of Yakuza/Yankee manga and movies as a sign of underground camaraderie among clan members, but did not meet our eligibility criteria.

A total of fifteen manga featuring eighteen characters with explicit engagement with selfinjury were identified (see Appendix Table 4 for the list of manga analyzed). Of fifteen manga, there were eight shōjo manga (Memai, Tobira, LIFE, GALS!, Mondai no nai watashitachi, Aishiteruze Baby, NANA, Tokyo Children), five seinen manga (eleGY, Last Menhera, Jisatsu Circle, G senjō Heaven's Door, Onani Master Kurosawa), one josei manga (Pietà), and one Boy's Love (CUT). No shōnen manga met our eligibility criteria. ${ }^{4}$ Each manga was further scrutinized to identify scenes depicting self-injury. In cases where self-injury appeared more than once in the story, each scene was recorded as a separate event. A total of forty scenes of self-injury were depicted among the sample with nine out of eighteen characters $(50 \%)$ portrayed as engaging in self-injury more than once. The year when the scene of self-injury appeared in each manga ranged from 2000-2017, with 75\% ( $\mathrm{n}=30)$ appearing during 20002005.

\section{Content analysis}

The method of content analysis was employed, combining quantitative and qualitative approaches. Informed by previous quantitative content analysis of movies featuring self-injury (Whitlock, Purington, and Gershkovich 2009; Trewavas, Hasking, and McAllister 2010), two authors first collaboratively developed a coding rubric to capture: 1) demographic data of the characters who self-injure (i.e. gender, age, occupation, sexual orientation, whether the characters are portrayed as engaging in habitual self-injury);2) methods of self-injury depicted (e.g., cutting, burning, hitting); 3) locations of self-injury on the body (e.g. wrist, forearm, thigh); 4) presence of other characters at the scene of self-injury; and 5) mental and/or physical health 
intervention after self-injury. Two authors then individually read five manga each to qualitatively analyze: 6) events that triggered self-injury; 7) degree of suicidal intent (e.g., overt, implied, none); 8) consequences of self-injury; and 9) perceived functions of self-injury. In this process, perceived functions of self-injury were determined in accordance with the antecedents and consequences implicitly and explicitly portrayed in narratives. As manga contains a complex system of symbolic meaning combining multiple visual and textual subcodes, the authors paid close attention not only to plots, characters' facial expressions and dialogues but also backgrounds (e.g., tones of the scene), onomatopoeia, frames, and characters' interior monologues implying particular meanings associated with each self-injurious act. Klonsky's (2007) seven-function model also provided a guiding framework for coding of the perceived functions. The seven functions include: affect regulation, anti-dissociation, anti-suicide, interpersonal boundaries, interpersonal influence, self-punishment, and sensation seeking.

After two iterations, the coding rubric was finalized. The first author coded all forty scenes, while two trained research assistants independently coded $50 \%$ of the sample each using the final rubric to capture the aforementioned nine elements. Agreement between two coders (the first author and one of the research assistants) was on average 95\%, ranging from $100 \%$ (demographic characteristics, methods of self-injury) to $82 \%$ (perceived functions of selfinjury). During the coding process, the first author and the research assistants took notes of their thought process and ensured interpretative consistency by team discussion. Discrepancies among coders were discussed until consensus was achieved.

\section{Results}

\section{Character demographics}

Table 1 presents the demographic attributes of eighteen characters who self-injure in the sampled manga. A salient gender difference was found in the characters, with sixteen out of eighteen characters being female $(88.9 \%)$. All but one character $(94.5 \%)$ were in their adolescence aged between thirteen and eighteen years old, being in high school or at junior

Table 1 Demographics of eighteen characters depicted as engaging in self-injury in Manga

\begin{tabular}{ll}
\hline & Characters $(\mathrm{N}=18)$ \\
\hline Gender & \\
Female & $16(88.9 \%)$ \\
Male & $2(11.1 \%)$ \\
Age & \\
15 or younger & $2(11.1 \%)$ \\
$16-18$ & $15(83.3 \%)$ \\
Over 18 & $1(5.6 \%)$ \\
Occupation & \\
Junior high school student & $2(11.1 \%)$ \\
High school student & $15(83.3 \%)$ \\
Other & $1(5.6 \%)$ \\
Sexual orientation & \\
Heterosexual & $16(88.9 \%)$ \\
Non-heterosexual & $2(11.1 \%)$ \\
Types of engagement with self-injury & \\
One-time only & $5(27.8 \%)$ \\
Habitual & $13(72.2 \%)$ \\
\hline
\end{tabular}


high school. The youngest age of onset depicted in those flashback scenes is grade four (nine to ten years old). In general, characters are portrayed as heterosexual, except for two characters, the female protagonist of Pietà (Haruno 2000) and the male protagonist of CUT (Kawayui 2003) who are depicted as in non-heterosexual romantic relationships. Characters who selfinjure tended to be main characters in the narrative $(77.8 \% \mathrm{n}=14)$ with the story unfolding through their perspectives. These characters' internal thoughts are often expressed through thought bubbles or narrations. Thirteen characters $(72.2 \%)$ are portrayed as recurrently engaging in self-injury, suggested by visible scars or through flashback scenes that reveal their past history.

\section{Depictions of self-injury}

Of the forty self-injury scenes, thirty-five (87.5\%) feature graphic depictions of self-injury in action, while five scenes allude to the act through visual depictions of bleeding wounds or scars with characters' accounts or inner thoughts. Four of the forty scenes of self-injury are flashbacks in which the characters retrospectively recall their past self-injury and events that triggered the act. Of the forty scenes examined, cutting is the most prominent method $(87.5 \%$, $\mathrm{n}=35)$, followed by stabbing $(7.5 \%, \mathrm{n}=3)$ and burning $(5 \%, \mathrm{n}=2)$. In terms of wound locations, self-injury is performed most often on wrists $(47.5 \%, \mathrm{n}=19)$ and on arms $(40 \%, \mathrm{n}=16)$, then less frequently on thighs $(5 \%, \mathrm{n}=2)$, hands $(5 \%, \mathrm{n}=2)$ and neck $(\mathrm{n}=1)$. Two characters selfinjure multiple body parts (See Table 2$)$. In $85 \%$ of the scenes examined $(n=34)$, characters self-injure alone in a private space such as a bathroom or a bedroom to conceal their behaviours. In six scenes (15\%), characters engage in self-injury in the presence of others (e.g., friends, families) to shock the person in presence or to express belonging to a group. In the majority of scenes examined $(n=34,85 \%)$, characters engaging in habitual self-injury feel they would be discriminated against if others discover their self-injury and thus conceal their scars with wristbands or long sleeves.

\section{Functions of self-injury and interventions}

The perceived primary functions of self-injury vary across the forty scenes (Table 3 ). The most conspicuous is affect regulation $(55 \%, \mathrm{n}=22)$ in which self-injury is depicted as a strategy to

Table 2 Self-injury depicted in forty scenes examined. $*$ The total percentage for wound locations is not $100 \%$, as some characters selfinjure multiple body parts

\begin{tabular}{ll}
\hline & Self-injury Scenes $(\mathrm{n}=40)$ \\
\hline $\begin{array}{l}\text { Method of self-injury } \\
\text { Cutting }\end{array}$ & $35(87.5 \%)$ \\
Stabbing & $3(7.5 \%)$ \\
Burning & $2(5 \%)$ \\
Wound locations* & \\
Wrist & $19(47.5 \%)$ \\
Arm & $17(42.5 \%)$ \\
Thigh & $3(7.5 \%)$ \\
Hand & $2(5 \%)$ \\
Neck & $1(2.5 \%)$ \\
Concealment of self-injury & \\
Covert/alone in private space & $34(85 \%)$ \\
Overt/in presence of others & $6(15 \%)$ \\
\hline
\end{tabular}


Table 3 Functions of self-injury and interventions
Scenes $(n=40)$

\begin{tabular}{ll}
\hline Functions & \\
Affect regulation & $22(55 \%)$ \\
Interpersonal influence & $6(15 \%)$ \\
Suicide Attempt & $5(12.5 \%)$ \\
Self-punishment & $4(10 \%)$ \\
Anti-dissociation & $2(5 \%)$ \\
Hallucination-driven & $1(2.5 \%)$ \\
Interventions & \\
None & $29(72.5 \%)$ \\
Unspecified & $6(15 \%)$ \\
Home first aid & $3(7.5 \%)$ \\
Hospitalization & $1(2.5 \%)$ \\
Psychological treatment & $1(2.5 \%)$ \\
\hline
\end{tabular}

alleviate acute negative emotion or aversive affective arousal (Klonsky, 2007) triggered by events such as bullying, friendship dissolution, conflict with family, or childhood trauma. The majority of scenes make no reference to a specific mental disorder (e.g., Borderline Personality Disorder, anxiety disorder) except for two scenes where characters are depicted as suffering from substance abuse (Memai) or depression (Tokyo Children).

For some of the characters who engage in habitual self-injury, the act tended to serve a single function (e.g., coping with emotional distress) despite being triggered by different antecedents. For others with recurrent self-injury, the meaning associated with self-injury varies depending on the motivation at the time, the relationship with the others in presence, and the frame of reference drawn to interpret the act. For example, a young female protagonist of Tobira (Momochi 2002) engages in self-cutting twice through the story; the first time is to express a blood oath of friendship with her classmate who habitually self-injures, and the second time is to attempt suicide in front of her mother. The protagonist, Manatsu, flexibly interprets self-injury first as a gesture of social bonding, then as a means to communicate her suicidality to her mother.

In most scenes analyzed $(75 \%, \mathrm{n}=30)$, self-injury is portrayed as independent from suicidal thoughts or behaviour. In Last Menhera, for example, the protagonist Sumire describes her recurrent self-cutting as a way of "enduring the pain of living" (Amano and Ise 2016, 56), rather than terminating her life. In five scenes $(12.5 \%)$ characters are depicted as having overt or implied suicidal intent. Among these scenes three characters attempt suicide by wristcutting, while two attempt suicide by jumping or intoxication in addition to cutting.

In four scenes $(10 \%)$, characters engage in self-injury to punish or invalidate themselves. This tendency is particularly salient in LIFE (Suenobu, 2002-2009; 20 volumes) quoted at the beginning of this article. The protagonist, Ayumu, is portrayed as shy and introverted, engaging in recurrent self-cutting as she feels she "does not deserve" to be happy (Suenobu 2002 , 97). In two scenes (5\%), characters injure themselves in a dissociative state. For example, in Pietà (Haruno 2000), the protagonist, Rio (a female high school student), is portrayed as cutting herself after having a flashback nightmare of her vicious stepmother. She is depicted as though not noticing her self-cutting until blood is dripping on the kitchen floor. Regaining a sense of self, Rio sinks on the floor with her arms wrapped around knees, faintly murmuring "Help" (19).

The majority of characters are not in any form of psychiatric treatment when engaging in self-injury. With respect to consequences of self-injury, in twenty-nine of forty scenes 
examined (72.5\%), self-injury does not result in any treatment or intervention. Six scenes $(15 \%)$ were categorized as "unspecified" because these scenes depict either the character recalling a past self-injury episode, or the story stops right at the moment of self-injury then leaps to a few days/months later with no reference to whether a treatment or intervention was offered to the character. There is little direct depiction of mental health treatment provided to characters after self-injury, except for one manga (Tobira) in which the mother of the protagonist saw a psychiatrist for advice after her daughter's wrist-cutting. In terms of informal support, ten characters $(55.6 \%)$ receive support from partners and friends, while parents and siblings seldom served as a source of support. The reactions of partners and close friends tended to be empathetic and contributing to the characters' recovery from self-injury, while parents, siblings and distant peers (e.g., classmates) are shown to be indifferent or react aversively to the character. In some of the manga examined, family members are portrayed as a direct trigger of self-injury. For example, in Mondai no nai watashitachi (Kimura and Ushida 2003, 3 volumes), a high school girl, Midori, faces constant pressure from her mother to succeed in school, marry a rich man, and take the mother out of her unhappy marriage. Midori feels distressed by the selfish dream that her mother imposes upon her and engages in recurrent self-injury until she meets the story's protagonist Mio at school and receives emotional support.

An emergent conceptualization of self-injury was also observed. While self-injury itself does not serve a distinct identity label (i.e., no character is called a "wrist-cutter" or "selfinjurer"), in two seinen manga (eleGY, Last Menhera) published in 2012 and after, female characters who self-injure are coined "menhera" (a derivation of "mental health-er," a person with mental instability) ${ }^{5}$ by other characters or superimposed texts. In both manga, the menhera girls are depicted as isolated, mentally unstable, and highly dependent on male protagonists who are interested in having a romantic/sexual relationship with them. The female protagonist Sumire in Last Menhera (Amano and Ise 2016) also engages in promiscuous sexual activity to combat feelings of emptiness until developing a stable relationship with the male protagonist.

\section{Discussion}

The current study aimed to offer a close reading of scenes in Japanese manga featuring selfinjury. We explored how self-injury has been represented in Japanese manga since 2000, focusing on self-injuring characters, the perceived functions of the behaviour, as well as the presence and absence of help-seeking among the characters. Results indicate that manga's depiction of self-injury are largely congruent with previous research on self-injury in English films (Whitlock, Purington, and Gershkovich 2009; Trewavas, Hasking, and McAllister 2010; Bareiss 2017), in which characters who self-injure are predominantly heterosexual female in their late teens, engaging in habitual self-cutting. Although there are a few male self-injuring characters, the gendered perspective still permeates the sampled manga.

Likewise, functions of self-injury mirror those identified in previous studies and clinical research (e.g., Klonsky 2007; Klonsky et al. 2015). Most characters who self-injure are portrayed as using self-injury as a strategy to cope with negative emotions, punish themselves, or interrupt a dissociative episode rather than as an act of suicide attempt. In two of five scenes in which characters are depicted to have overt or implied suicide intent, wrist-cutting is used in combination with more lethal methods such as jumping and intoxication, implying perceived 
low lethality of wrist-cutting. In alignment with Ishige's (2006) observation that wrist-cutting no longer signals suicidal ideation in the post-1980 manga, this finding indicates that while the depiction of wrist-cutting may still evoke a traditional cultural reading that connects the act with suicidal intent, the interpretation of habitual wrist-cutting as a coping mechanism to endure "the pain of living" (Amano and Ise 2016) may be increasingly incorporated into the Japanese popular cultural imagination. Given that research indicates habitual engagement in self-injury elevates suicide risk and provides a "gateway" for suicide (Whitlock et al. 2013), potential implications of this interpretation warrants caution.

There is a general lack of help-seeking among self-injuring characters. Across the forty scenes examined, self-injury is portrayed as a stigmatized behaviour that makes the characters feel ashamed, and they conceal their behaviours and scars from others. However, more than half of the characters who self-injure eventually receive emotional support from significant others who help them recover from habitual self-injury. While a similar finding was reported in a previous study in which self-injuring characters receive informal support from friends and family (Trewavas, Hasking, and McAllister 2010), in the present study the sources of support are primarily romantic partners and close friends; reaction by families, parents in particular, to the self-injuring characters tend to be unsupportive and aversive, or even triggering, like the mother in Mondai no nai watashitachi (Kimura and Ushida 2001-2003) who desires to use her daughter to compensate for her unhappy life. In such a context, character's self-injury is portrayed as a form of resistance against repressive parental domination, similar to Bareiss's (2017) analysis of films featuring self-injuring girls. In addition, the absence of parental support for self-injury can also be explained by the prevalence of a bildungsroman theme in both shōnen and shōjo manga, in which conflict with parental figures often serve as a catalyst for self-actualization for young characters.

In a related vein, we observed two contrasting perspectives toward young girls who selfinjure. On one hand, in shöjo manga, characters who self-injure are primarily protagonists of the narrative, whose internal struggles and causes of self-injury are delineated with extensive detail from a first person point of view. As shojo manga serve young female readers as "a model for reality" (Masuda 2015), these manga may invite readers to walk through life struggles with the protagonists and frame self-injury as a maladaptive but understandable response to contemporary pressures placed upon young girls. The depiction of self-injury as a gesture of friendship or group membership also reflects the female characters' desire for escaping from parental control and belonging instead to a group of peers who accept them.

On the other hand, seinen manga aimed at adult male readers portray girls who self-injure from the perspective of male protagonists. Of particular interest is the emergence of "menhera" characters in two seinen manga published since 2012, in which male protagonists are attracted to menhera girls who exhibited mental instability, fear of abandonment and insecure romantic attachments. For these menhera girls, self-injury is not just an act of affect regulation but also an identity label that shapes their role in the narrative. The menhera character can be seen as a twisted variant of the damsel in distress, a classic narrative trope in literature that involves young, attractive, and helpless mistresses waiting to be rescued by a hero. They were placed in a predicament not by a monster or a villain but by mental illness that makes them prone to risky behaviour such as self-injury or sexual promiscuity. Contrary to characters that self-injure in shojo manga, these menhera girls are clearly subjected to the male gaze that objectifies and fetishizes the female self-injured body, while attention is deflected from underlying causes of self-injury. Although it may be too naïve to believe that readers take such a portrayal at face value, this fetishized gaze toward menhera girls nonetheless provides its overwhelmingly male readers with a highly gendered interpretive repertoire. An inquiry into these two contrasting 
views would make a valuable contribution to the understanding of public perception on mental illness in Japan.

Furthermore, it would be meaningful for future work to explore depictions of subcultural and ritualistic self-injury in manga for male readers, particularly those themed Yakuza (Japanese mafia) and Yankee (gangster) that were excluded from the current study. In their content analysis of English films, Trewavas, Hasking, and McAllister (2010) report that male characters who self-injure engage in more diverse methods of self-injury than females. Exploring subculturally sanctioned body mutilations in shōnen, seinen and seijin manga targeting male readership may imply how these self-injuries have distinctive meaning in Japanese popular culture in contrast to the pathologized and highly gendered portrayal of self-injury explored in this study. In this process, applying a critical gender lens to these representations would substantially enrich future investigation. Moreover, future exploration into self-published doujinshi (indie comics) and web comics with self-injuring characters would further expand this field of inquiry. With the advancement of indie comic markets and self-publishing online tools, Japanese readers are increasingly exposed to less filtered and more direct depictions of violence and human suffering including self-injury, suicide, and other mental health issues. This line of research could analyze how this emergent subculture represents self-injury in comparison with mainstream manga, focusing particularly on the "menhera" characters and on unique behavioural and affective attributes they embody.

The current findings have several implications for future research and intervention of selfinjury. First, manga has been deeply embedded in contemporary Japanese society to the extent that its power to shape public understanding of mental health issues cannot be underestimated. Manga representations of self-injury examined in this study offer a complex commentary on self-injury and have likely influenced, to varying degrees, readers' perceptions of how people who self-injure could be like and should be treated. As manga is considered providing young readers "textbooks for living" (Masuda 2015, 28), some readers may turn to these manga to make sense of their own engagement in self-injury. The portrayal of emotional support from partners and close friends observed in this study may induce a sense of hope among readers who self-injure, while reducing the feeling of social isolation commonly reported by youth engaging in self-injury (Whitlock et al. 2013). Meanwhile, the general absence of support from family (parents in particular) found in this study is concerning, because this tendency may perpetuate existing stigma associated with self-injury and promote the vilification of parents.

Second, actual impacts of manga on readers should be examined in future research. Although there is as yet no empirical evidence if exposure to the portrayal of self-injury in manga (and popular media in general) may induce contagion, ${ }^{6}$ researchers have addressed concern that recurrent exposure to fictional/non-fictional self-injury stories may result in narrative reinforcement (Whitlock, Purington, and Gershkovich 2009), which, for better or worse, justify self-injury related behavioural choices. Indeed, remarkably little has been written about the positive therapeutic potential of manga for readers with mental health issues. Researching further into how readers of different types interpret manga and the potential use of manga in treating people who self-injure may provide a new avenue into improving support to those engaging in self-injury.

Finally, the present study makes a unique contribution to the emergent study of graphic medicine (Williams 2012) by illuminating how the medium of comic can be used to understand subjective experience of self-injury. For readers residing in other countries than Japan, the current study findings may be of particularly salience, as they offer an interesting window into a unique cultural interpretation of self-injury in Japan and suggest the potential of crosscultural exploration into cultural attitudes toward self-injury and related mental health issues. 
Given the increasing visibility of Japanese popular media including manga in international markets (Ito 2010), much more work could be done in this area, including the academic appraisal of manga representations of mental health in and outside Japan, and how such manga are perceived by Japanese and non-Japanese audiences.

Acknowledgements We thank Masako Yanagimoto and Takumi Seko for their assistance with coding.

\section{Endnotes}

${ }^{1}$ Promoting this line of definition, a group of psychiatrists and researchers proposed a term "non-suicidal selfinjury (NSSI)" to the Diagnostic and Statistical Manual of Mental Disorders: DSM-5 criteria (American Psychiatric Association 2013). Although NSSI did not become a standalone, formal diagnosis, the term is now widely used among the clinical community allowing clinicians to treat self-injury as a mental illness. Critical scholars of health such as Amy Chandler (2014) voiced concern over how this trend towards pathologization would impact individual and public understandings of self-injury.

${ }^{2}$ Although the history of Japanese manga can date back to the seventh century (Ito 2005), in this article manga refers to modern Japanese graphic novels popularized after World War II that combines traditional Japanese iconography with American cartoon and cinematic techniques. Fredrik Schodt's seminal book Manga! Manga!: The World of Japanese Comics (1986) provides a comprehensive overview of the history of Japanese manga until the 1980s. Kinko Ito's chapter (2005) also provides a succinct summary of Japanese manga history from ancient times to the early twenty-first century. It is worth noting here that this article uses the term "manga" both as a singular and a plural noun.

${ }^{3}$ A 2018 report by the All Japan Magazine and Book Publishers and Editors Association (AJPEA)'s 2018 estimated the total sales of the manga industry in 2017 (physical and digital platforms combined) as 433 billion yen (equivalent to $\$ 3.92$ billion USD), which generated nearly double the revenues of the local film industry (228 billion yen, Motion Picture Producers Association of Japan, 2018). Although sales of print manga have been declining since the mid-1990s, the rise of denshi comic (digital comics) kept the market afloat. Manga also plays a vital role in Japan's "media mix," a character-based marketing strategy to distribute content across multiple media platforms (Ito 2010). Popular manga series often provide characters and plots for other platforms such as anime (animation), games, films, TV dramas, advertising and even political campaigns that together establish manga's pervasive presence in Japanese cultural landscape.

${ }^{4}$ There are two potential explanations that may account for the absence of shōnen manga. First, in shōnen manga, slice-of-life genre is popular, but not as dominant as in other genre (e.g., shöjo manga). Self-injury depicted as happening in imaginary worlds did not meet this study's inclusion criteria. Second, when shōnen manga portray self-injurious behaviours, the acts tend to take a form of physical aggression against objects, rather than aggression against oneself. For example, it is a common scene among shōnen and seinen manga wherein a male protagonist punches a wall or window, damages the object, and consequently hurts himself. Such a portrayal did not meet the study definition of self-injury being a deliberate hurting of one's body, because the injury is the consequence, rather than the purpose of the act. As pointed out by one reviewer, the absence of shōnen manga in our sample may also suggest a gendered understanding of self-injury penetrating Japanese popular culture. Future research focusing on gender difference in the depiction of aggressive behaviours among Japanese manga would provide further insight.

5 The term "menhera" spawned from a mental health discussion board on 2-channel (2-chan), a Japanese massive anonymous online forum. Although the term was originally used by people struggling mental health issues to address themselves, it increasingly carries negative, derogatory connotations in Japanese popular culture.

${ }^{6}$ In Japan, potential psychological and behavioural impacts of manga on readers, especially adolescents and young adults, have long been the topic of contested debate. Violent and sexually explicit expressions in manga for young readership came under recurrent critique by parent associations, school authorities, and policy makers who insisted manga has harmful impact on children. Most recently in 2010, the Tokyo Metropolitan Government tried to ban the sexually explicit expression in manga and anime through the revision of the Tokyo Metropolitan Youth Healthy Development Ordinance. The Ordinance was amended to extend the definition of "harmful content" to include "hijitsuzai seishōnen" (non-existent youth). Facing massive protest from writers and publishers, this proposal removed 'non-existent youth' and received approval by the Metropolitan Assembly in December 2010 (Asahi Shimbun 2010)

Funding Information This study was supported by Wilfrid Laurier University's Contract Academic Staff Research Fund granted to the first author (Grant Code: 247113). 


\section{Appendix}

Table 4 List of Manga Analyzed

\begin{tabular}{|c|c|c|c|c|c|}
\hline Title & Author(s) & $\begin{array}{l}\text { Year (when } \\
\text { self-injury } \\
\text { was depicted) }\end{array}$ & Genre & $\begin{array}{l}\text { Numbers of } \\
\text { characters } \\
\text { who self-injure }\end{array}$ & $\begin{array}{l}\text { Numbers of } \\
\text { self-injury } \\
\text { scenes } \\
\text { depicted }\end{array}$ \\
\hline $\begin{array}{l}\text { Aishiteruze Baby } \\
\quad \text { (I love you, Baby) }\end{array}$ & Maki, Yoko & 2003 & shōjo (girls) & 1 & 3 \\
\hline GALS! & Fujii, Mihona & 2002 & shōjo (girls) & 1 & 1 \\
\hline LIFE & Suenobu, Keiko & 2002,2003 & shōjo (girls) & 1 & 7 \\
\hline Memai (Vertigo) & Momochi, Reiko & 2000 & shōjo (girls) & 1 & 1 \\
\hline $\begin{array}{l}\text { Mondai no nai } \\
\text { watashitachi } \\
\text { (We have no } \\
\text { problem) }\end{array}$ & $\begin{array}{l}\text { Kimura, Aya \& } \\
\text { Ushida, Maki }\end{array}$ & 2002,2003 & shōjo (girls) & 1 & 4 \\
\hline NANA & Yazawa, Ai & 2005 & shōjo (girls) & 1 & 1 \\
\hline Tobira (The Door) & Momochi, Reiko & 2002 & shōjo (girls) & 2 & 5 \\
\hline Tokyo Children & Mimori, Taeko & 2005,2006 & shōjo (girls) & 2 & 3 \\
\hline eleGY & $\begin{array}{l}\text { Ooiwa, Kenji \& } \\
\text { Izumi, Kazuyoshi }\end{array}$ & 2012 & seinen (young men) & 1 & 1 \\
\hline $\begin{array}{l}\text { G senjō Heaven's } \\
\text { Door (Heaven's } \\
\text { Door on the G } \\
\text { String) }\end{array}$ & Nihonbashi, Yoko & 2003 & seinen (young men) & 1 & 1 \\
\hline $\begin{array}{l}\text { Jisatsu Circle (Suicide } \\
\text { Circle) }\end{array}$ & Furuya, Usagimaru & 2002 & seinen (young men) & 1 & 2 \\
\hline Last Menhera & $\begin{array}{l}\text { Amano, Shuninta } \\
\text { \& Ise, Katsuyoshi }\end{array}$ & 2016 & seinen (young men) & 2 & 7 \\
\hline $\begin{array}{l}\text { Onani Master } \\
\text { Kurosawa } \\
\text { (Masterbater } \\
\text { Kurosawa) }\end{array}$ & $\begin{array}{l}\text { Yokota, Takuma } \\
\quad \text { \& Ise, Katsuyoshi }\end{array}$ & 2008 & seinen (young men) & 1 & 1 \\
\hline Pietà & Makino, Nanae & 2000 & josei (young women) & 1 & 2 \\
\hline CUT & Kawayui, Toko & 2003 & Boy's Love & 1 & 1 \\
\hline
\end{tabular}

\section{References}

All Japan Magazine and Book Publishers and Editors Association (AJPEA). 2018. Shuppan Geppō Ichigatsu Gō (Publisher's Monthly Report: January 2018). Accessed June 28, 2018. https://www.ajpea.or.jp/book/2-1801 /index.html.

Amano, Shuninta and Katsuyoshi Ise. 2016. Last Menhera. Tokyo: Souyou-sha.

American Psychiatric Association. 2013. Diagnostic and Statistical Manual of Mental Disorders (DSM-5®). American Psychiatric Pub.

Asahi Shimbun (Asahi Newspaper). 2010. "Seibyosha manga hanbai kisei: Tokyo-to no jourei kaisei an gakaketsu, seiritsu/Tokyo Bans Sales of Sexually Explicit manga: The Tokyo Metropolitan Government Revised Bill was Approved and Reacted." December 15. Accessed August 8, 2018. http://www.asahi. com/national/update/1215/TKY201012150417.html.

Asano, Mizuho. 2015. "Future Prospects for Studying Self-injurious Behaviors and Those Who Inflict Them." Rikkyo Clinical Psychology Research 9:13-23.

Bareiss, Warren. 2017. "Adolescent Daughters and Ritual Abjection: Narrative Analysis of Self-injury in Four US Films.” Journal of Medical Humanities 38 (3): 319-337.

Brickman, Barbara Jane. 2004. "Delicate' Cutters: Gendered Self-mutilation and Attractive Flesh in Medical Discourse.” Body \& Society 10 (4): 87-111. 
Brumberg, Joan Jacobs. 2006. “Are We Facing an Epidemic of Self-Injury?” Chronicle of Higher Education 53 (16): B6-B9.

Chandler, Amy. 2014. "Narrating the Self-injured Body." Medical Humanities 40 (2): 111-116.

Chandler, Amy, Fiona Myers, and Stephen Platt. 2011. "The Construction of Self-injury in the Clinical Literature: A Sociological Exploration.” Suicide and Life-Threatening Behavior 41 (1): 98-109.

Cohn, Neil. 2010. “Japanese Visual Language: The Structure of manga.” In Manga: An Anthology of Global and Cultural Perspectives, edited by Toni Johnson-Woods, 187-203. New York: Continuum International Publishing Group Inc

Fujii, Mihona. 1998-2002. GALS! Tokyo: Shūei-sha

Haruno, Namie. 2000. Pietà. Tokyo: Shūei-sha.

International Society for the Study of Self-Injury. 2018. Fast Facts. Accessed May 08, 2018. http://itriples. org/redesadmin $15 /$ fast-facts/2016.

Ishige, Naoko. 2006. Jishō no Bunka-shi (Cultural History of Self-Injury). Kokoro no Kagaku (Science of Mind) 127 (5): 96-105.

Ito, Hiroto, Richard G. Frank, Yukiko Nakatani, and Yusuke Fukuda. 2013. "Mental Health Care Reforms in Asia: The Regional Health Care Strategic Plan: The Growing Impact of Mental Disorders in Japan." Psychiatric Services 64 (7): 617-619.

Ito, Kinko. 2005. "A History of manga in the Context of Japanese Culture and Society." The Journal of Popular Culture 38 (3): 456-475.

Ito, Mizuko. 2010. "Mobilizing the Imagination in Everyday Play: The Case of Japanese Media Mixes." In Mashup cultures, edited by Stefan Sonvilla-Weiss, 79-97. Heidelberg: Springer.

Kawayui, Tōko. 2003. Cut. Tokyo: Biburosu.

Kimura, Aya, and Maki Ushida. 2001-2003. Mondai no nai watashitachi (We Have No Probl). Tokyo: Shūeisha

Kinsella, Sharon. 1995. "Cuties in Japan: Women, Media and Consumption in Japan." In Women, Media and Consumption in Japan, edited by Lise Skov and Brian Moeran, 220-253. Honolulu: University of Hawaii Press.

Kishi, Yukiko, Tomoko Matsumura, Naoko Murishige, Yuko Kodama, Nobuyo Hatanaka, Morihito Takita, Kenjiro Sakamoto, Tamae Hamaki, Eiji Kusumi, and Kazuhiko Kobayashi. 2011. "Internet-based Survey on Medical manga in Japan.” Health Communication 26 (7): 676-678.

Klonsky, David E. 2007. "The Functions of Deliberate Self-injury: A Review of the Evidence." Clinical Psychology Review 27 (2): 226-239.

Klonsky, David E, Catherine R Glenn, Denise M Styer, Thomas M Olino, and Jason J Washburn. 2015. "The Functions of Nonsuicidal Self-injury: Converging Evidence for a Two-factor Structure." Child and Adolescent Psychiatry and Mental Health 9 (1): 44.

Masuda, Nozomi. 2015. "Shojo Manga and Its Acceptance: What is the Power of Shojo manga?" In International Perspectives on Shojo and Shojo Manga: The Influence of Girl Culture, edited by Masami Toku, 23-31. New York: Routledge

Matanle, Peter, Kuniko Ishiguro, and Leo McCann. 2014. "Popular Culture and Workplace Gendering among Varieties of Capitalism: Working Women and their Representation in Japanese Manga." Gender, Work \& Organization 21 (5): 472-489.

Matsumoto, Toshihiko, Fumi Imamura, Yasuhiko Chiba, Yotaro Katsumata, Masahiko Kitani, and Tadashi Takeshima. 2008. "Prevalences of Lifetime Histories of Self-cutting and Suicidal Ideation in Japanese Adolescents: Differences by Age.” Psychiatry and Clinical Neurosciences 62 (3): 362-364.

Matsumoto, Toshihiko, Fumi Imamura, and Yotaro Katsumata. 2009. "What Difficulties do School Nurses have in Treatment of the Self-injuring Students?: A Study Using a Self-reporting Questionnaire at the Workshops for School Nurses." Seishin Igaku (Clinical Psychiatry) 51(8): 791-799.

Matsuoka, Rieko, Ian Smith, and Mari Uchimura. 2011. "Discourse Analysis of Encouragement in Healthcare Manga.” Journal of Pan-Pacific Association of Applied Linguistics 15 (1): 49-66.

Momochi, Reiko. 2000. Memai (Vertigo). Tokyo: Kōdan-sha 2002. Tobira (the door). Tokyo: Kōdan-sha.

Motion Picture Producers Association of Japan. 2018. "Statistics of Film Industry in Japan." Accessed June 27 2018. http://www.eiren.org/statistics e/index.html

Muehlenkamp, Jennifer J, Laurence Claes, Lindsey Havertape, and Paul L Plener. 2012. "International Prevalence of Adolescent Non-suicidal Self-injury and Deliberate Self-harm." Child and Adolescent Psychiatry and Mental Health 6 (1): 10.

Nock, Matthew K, Thomas E Joiner Jr, Kathryn H Gordon, Elizabeth Lloyd-Richardson, and Mitchell J Prinstein. 2006. "Non-suicidal Self-injury among Adolescents: Diagnostic Correlates and Relation to Suicide Attempts.” Psychiatry Research 144 (1): 65-72.

Okada, Ryo, Iori Tani, Masashi Onishi et al. 2010. "Preavalence of Self-injurious Behaviours in Japanese Junior High School Students: A Census in a Single City.” Seishin Igaku (Clinical Psychiatry) 52 (12): 1209-1212. 
Schodt, Frederik L. 1986. Manga! Manga!: The world of Japanese Comics. Tokyo: Kōdansha International. Suenobu, Keiko. 2002-2009. LIFE. Tokyo: Kōdan-sha.

Swannell, Sarah V., Graham E. Martin, Andrew Page, Penelope Hasking, and Nathan J. St John. 2014. "Prevalence of Nonsuicidal Self-injury in Nonclinical Samples: Systematic Review, Meta-analysis and Meta-regression.” Suicide and Life-Threatening Behavior 44 (3): 273-303.

Takahashi, Satoru and Hideyuki Fujiu. 2015. "Prevalence and Psychological Functions of Self-injury among Juvenile Delinquents.” Japanese Journal of Counselling Science 48:75-85.

Trewavas, Christopher, Penelope Hasking, and Margaret McAllister. 2010. "Representations of Non-suicidal Self-injury in Motion Pictures.” Archives of Suicide Research 14 (1): 89-103.

Unser-Schutz, Giancarla. 2015. "What Text can tell us about Male and Female Characters in shōjo-and shōnenmanga." East Asian Journal of Popular Culture 1 (1): 133-153.

Whitlock, Janis, Amanda Purington, and Marina Gershkovich. 2009. "Media, the Internet, and Nonsuicidal Selfinjury.” In Understanding Nonsuicidal Self-injury: Origins, Assessment, and Treatment, edited by Matthew K Nock, 139-155. Washington DC: American Psychological Association.

Whitlock, Janis, Jennifer Muehlenkamp, John Eckenrode, Amanda Purington, Gina Baral Abrams, Paul Barreira, and Victoria Kress. 2013." Nonsuicidal Self-injury as a Gateway to Suicide in Young Adults." Journal of Adolescent Health 52 (4): 486-492.

Williams, Ian CM. 2012. “Graphic medicine: Comics as Medical Narrative.” Medical Humanities 38 (1): 21-27.

Yamaguchi, Akiko, Toshikiko Matsumoto, Chizue Kondo, Toshinori Odawara, Naoki Takeuchi, Kenji Kosaka, and Hajime Sawada. 2004. "Prevalence of Self-mutilation in Japanese Uiversity Students: A Study using Self-reporting Questionnaire.” Seishin Igaku (Clinical Psychiatry) 46:473-479.

Publisher's Note Springer Nature remains neutral with regard to jurisdictional claims in published maps and institutional affiliations. 